\title{
Cadaverine and burying in the laboratory rat
}

\author{
CHRISTOPHER P. MONTOYA, ROBERT J. SUTHERLAND, and IAN Q. WHISHAW \\ University of Lethbridge, Lethbridge, Alberta TIK 3M4, Canada
}

\begin{abstract}
When rats housed in an environment that contained wood-shaving bedding material were given normal food pellets or food pellets soaked with cadaverine, they buried more cadaverinesoaked pellets than normal pellets. They also hoarded and ate cadaverine-soaked pellets and ate a mash saturated with cadaverine. Thus, cadaverine is not noxious to rats. The fact that they bury substances soaked with it indicates that burying can be a nondefensive unconditional species-typical response. We suggest that given the rich behavioral repertoire of rats, behavioral profiles consisting of a number of different tests are necessary to establish the transsituationality of the reinforcing valence of objects.
\end{abstract}

It was initially thought that when animals were exposed to aversive stimuli their responses were limited to fleeing, freezing, or attacking (Bolles, 1970). Hudson (1950), however, reported that if rats were shocked in the presence of a novel object, they covered that object with bedding. Subsequently, Pinel and Treit (1978) and Wilkie, MacLennan, and Pinel (1979) found that rats buried objects that had been paired with any of a variety of noxious stimuli. They argued that the repertoire of defensive behaviors available to rats is greater than was initially appreciated. They have also argued that all burying, whether conditioned or unconditioned, is defensive (Pinel, Hoyer, \& Terlecki, 1980).

Pinel et al. (1980) have shown that rats display approach and avoidance behaviors and bury wooden dowels soaked in cadaverine, a putrid substance that can emanate from decaying corpses. We have confirmed their finding, but in addition, we wanted to assess whether cadaverine is indeed aversive. In the present experiments, we assessed aversiveness by using eating and hoarding responses. Substantial work has shown that rats will not sample, eat, or hoard inherently noxious objects or objects that are made noxious by taste aversion conditioning, although they do bury them (Barnett \& Spencer, 1953; Wallace, 1979; Wilkie et al., 1979). Accordingly, we soaked food pellets in cadaverine to determine whether rats would eat, hoard, and bury the food. Even when normal food was available, the rats frequently preferred to eat, hoard, and bury the cadaverine-soaked pellets. Therefore, it appears that cadaverine is not aversive to rats and, more important,

This research was supported by a Natural Sciences and Engineering Research Council Summer Research Award to Chris Montoya and a Natural Sciences and Engineering Research Council Grant to Ian Q. Whishaw. We would like to thank Laura Montoya and Adria Allen for their assistance in the preparation of the manuscript. Chris Montoya is now attending the University of Calgary, Department of Psychology, 2500 University Drive, N. W., Calgary, Alberta T2N 1N4, Canada. Requests for reprints should be sent to I. Q. Whishaw, Department of Psychology, University of Lethbridge, 4401 University Drive, Lethbridge, Alberta T1K 3M4, Canada. that all burying need not be assumed to be defensive in nature.

\section{METHOD}

\section{Subjects}

The subjects were 24 male and 24 female adult Long-Evans rats born and reared in the University of Lethbridge psychology laboratory. They were individually housed and fed Purina Laboratory Chow pellets and water.

\section{Apparatus}

The hoarding apparatus consisted of six plywood alleys, each measuring $180 \mathrm{~cm}$ long $\times 20 \mathrm{~cm}$ wide $\times 25 \mathrm{~cm}$ high. There was a plywood startbox at one end of each alley that measured $25 \mathrm{~cm}$ long $\times 20 \mathrm{~cm}$ wide $\times 20 \mathrm{~cm}$ high. A hole in the startboxes permitted access to the alleys. The startboxes were painted black and were covered with a wooden lid; the alleys were painted white and covered with a glass lid. Water was available through spouts in the startboxes. Room illumination was $4 \mathrm{fc}$.

The burying apparatus was a $45 \times 45 \times 60 \mathrm{~cm}$ high wooden box with a glass front. Water was available through a spout $10 \mathrm{~cm}$ from the bottom. The floor of the box was covered with $8.5 \mathrm{~cm}$ of wood shavings. Illumination in the box was $4 \mathrm{fc}$.

\section{Procedure}

Burying. Six male and six female rats received a 24 -h habituation period in groups of six in the burying box. On the following days, the rats were placed individually for $20 \mathrm{~min}$ in the box, which now contained either a 3-cm-long cadaverine pellet (Day 1) or a normal pellet (Day 2). If the food pellets had been covered completely with shavings, they were classified as buried.

Hoarding. Eighteen male and 18 female rats received a 24-h habituation period individually in the hoarding alleys before testing. In this and other hoarding experiments, trials were begun in the afternoon and terminated $24 \mathrm{~h}$ later. The objects used were Purina Rat Chow pellets, all approximately $3 \mathrm{~cm}$ long. In each hoarding experiment, 15 normal Purina Rat Chow pellets and 5 cadaverine-soaked pellets were randomly placed $90-180 \mathrm{~cm}$ away from the startbox. If a pellet was carried into the startbox or to within $60 \mathrm{~cm}$ of the startbox, it was considered hoarded. Half-eaten and missing pellets were considered eaten.

\section{RESULTS}

Rats preferred to hoard and eat cadaverine significantly more than their normal food (Figure 1). The 


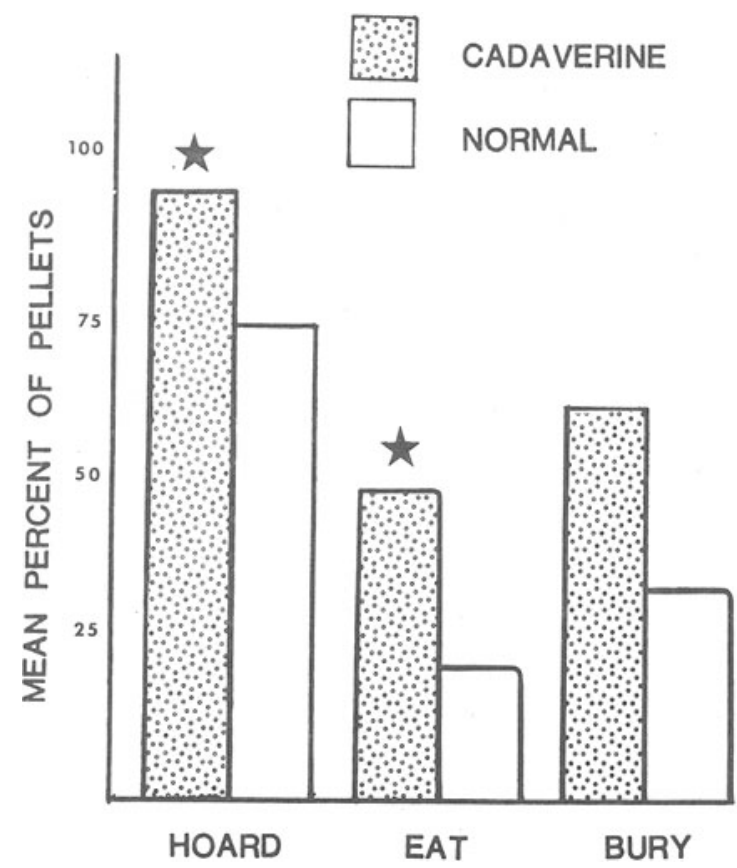

Figure 1. Mean percentage of available pellets hoarded, eaten, and buried. Solid bar: cadaverine-soaked pellets. Open bar: normal food pellets. Stars indicate a statistically significant difference.

animals hoarded $90.3 \%$ of the cadaverine pellets, compared with $73 \%$ of the normal pellets [males, $\chi^{2}(1)=$ $12.02, \mathrm{p}<.01$; females, $\left.\chi^{2}(1)=5.81, \mathrm{p}<.05\right]$. Males and females ate significantly more cadaverine pellets than normal pellets [males, $\chi^{2}(1)=6.65, \mathrm{p}<.01$; females, $\left.\chi^{2}(1)=54.15, p<.01\right]$. Female rats ate more cadaverine-soaked food than the male rats did $\left[\chi^{2}(1)=8.8, \mathrm{p}<.01\right]$.

A sex difference was found in burying of normal food pellets. No females buried normal food pellets, whereas four of the six males did bury them $\left[\chi^{2}(1)=\right.$ $5.89, \mathrm{p}<.05]$. Male rats buried four of six cadaverinesoaked pellets compared with three of six normal food pellets, and female rats buried three of six cadaverinesoaked pellets compared with no burial of normal food pellets $\left[\chi^{2}(1)=5.3, p<.05\right]$.

After the burying tests, we gave six male rats the opportunity to eat Purina mash mixed with different concentrations of cadaverine from a spatual inserted into their home cages. All of the rats persistently ate the mash, even though on some presentations we saturated the mash with cadaverine.

\section{DISCUSSION}

The present data establish that the burying of cadaverine should not be classified as defensive burying. In earlier reports of unconditioned burying by rats (Pinel et al., 1980; Pinel \& Treit, 1978; Wilkie et al., 1979), only objects assumed to be aversive were used to elicit defensive burying (i.e., cadaverine and tabasco sauce).
As rats tend not to hoard or eat aversive foods, we were able to demonstrate that the burying of cadaverine.by rats is not a response to an aversive stimulus. In fact, Norway rats prefer to eat 120 -h dead conspecifics vs. freshly dead conspecific (Carr, Landauer, Wiese, Marasco, \& Thor, 1979). These 120-h carcasses would contain a substantial amount of cadaverine, which forms as a result of the decarboxylation of lysine in the flesh. Parenthetically, a predilection for cadaverine might even be involved in the rat's species-typical consumption of putrifying carcasses. As a speculation, burying of cadaverine-soaked objects might be a form of hiding or food-storing behavior, or it might be directed toward modifying some aspect of the food's decomposition. We are reminded here of Bei Dan (100year-old eggs), eggs buried for extended periods in certain cultures to improve palatability.

Recently, Poling, Cleary, and Monaghan (1981) demonstrated that over a $24-\mathrm{h}$ period, male rats buried marbles and food pellets to the same extent as assumedly aversive-tasting quinine-soaked pellets, but they did not bury a spout that contained apple juice. As all stimuli did not elicit burying, Poling et al. felt that the burying of solids might be related to hoarding. They speculated that burying or nonaversive solids might be sensitive to variables that facilitate or inhibit hoarding. Our results are consistent with this notion.

In the case of cadaverine, Pinel et al. (1980) report that rats make cadaverine-soaked prods the focus of approach-avoidance behavior. Approach-avoidance behavior assumedly occurs in response to both conditioned and unconditioned aversive stimuli (Blanchard \& Blanchard, 1970a, 1970b, 1971). As rats also bury cadaverine prods after first showing approach-avoidance behaviors, Pinel et al. (1980) conclude that cadaverine is aversive, because both behaviors are assumed to be responses to aversive stimuli. Approach-avoidance behavior may be a response to the novelty of an object (Barnett, 1963), but this need not be taken as an indication that the object is aversive.

This experiment argues that, from naturalistic observations of wild rats and from corroborative laboratory experiments (also McKim \& Lett, 1979), cadaverine is nonaversive. Thus, it should not be assumed that all instances of burying are defensive in nature.

\section{REFERENCES}

Barnett, S. A. A study in behavior. Great Britain: Camelot Press, 1963.

Barnett, S. A., \& Spencer, M. M. Response of wild rats to offensive smells and tastes. British Journal of Animal Behavior, 1953, 1, 32-37.

Blanchard, R. J., \& Blanchard, D. C. Dual mechanisms in passive avoidance: I. Psychonomic Science, 1970, 19, 1-2. (a)

Blanchard, R. J., \& BlanchaRd, D. C. Dual mechanisms in passive avoidance: II. Psychonomic Science, 1970, 19, 3-4. (b)

Blanchard, R. J., \& BlanchaRd, D. C. Defensive reactions in the albino rat. Learning and Motivation, 1971, 2, 351-362.

Bolles, R. C. Species specific defense reaction and avoidance learning. Psychological Review, 1970, 71, 32-48.

Carr, W. J., Landauer, M. R. Wiese, R. E., Marasco, E., \& THOR, D. H. A natural food aversion in Norway rats. Journal of Comparative and Physiological Psychology, 1979, 93, 574-584.

Hudson, B. B. One-trial learning in the domestic rat. Genetic Psychology Monographs, 1950, 41, 99-145.

McKim, W. A., \& LetT, B. T. Spontaneous and shock induced burying in two strains of rat. Behavioral and Neural Biology, 1979, 26, 70-80.

Pinel, J. P. J., Hoyer, E., \& Terlecki, L. J. Defensive burying and approach-avoidance behavior in the rat. Bulletin of the Psychonomic Society, 1980, 16, 349-352. 
Pinel, J. P. J., \& Treit, D. Burying as a defensive response in rats. Journal of Comparative and Physiological Psychology, 1978, 92, 708-712.

Poling, A., Cleary, J., \& Monaghan, M. Burying in rats in response to aversive and non-aversive stimuli. Journal of the Experimental Analysis of Behavior, 1981, 35, 31-44.

WALLACE, R. J. Novelty and partibility as determinants of hoarding in the albino rat. Animal Learning \& Behavior, 1979, 7, 549-554.

Wilkie, D. M., Maclennan, A. J., \& Pinel, J. P. J. Rat defensive behavior: Burying noxious food. Journal of the Experimental Analysis of Behavior, 1979, 31, 299-306.

(Received for publication July 24, 1981.) 